\title{
IDENTIDADE, POLÍTICA E ELEIÇÃO NO ESTADO DO TOCANTINS: $1988-2010$
}

\author{
IDENTIDAD, POLÍTICA E ELECCIÓN EN EL ESTADO
}

DE TOCANTINS: 1988-2010

\author{
IDENTITY, POLITICS AND ELECTION IN THE STATE \\ OF TOCANTINS: 1988-2010 \\ Jean Carlos Rodrigues - Universidade Federal do Tocantins - Araguaína - Tocantins - Brasil \\ jeancarlos@uft.edu.br
}

\begin{abstract}
Resumo
0 artigo tem por finalidade discutir o processo de divisão regional e a ação de sujeitos sociais ao produzirem discursos regionalistas e representações simbólicas que legitimem tal reivindicação. Esta temática foi suscitada pelo debate em torno da divisão do estado do Pará, em 2011. Tomando o caso do estado do Tocantins como ponto de partida, procuramos demonstrar que a forma como tem sido conduzido o debate sobre as divisões regionais revela a reprodução de práticas sociais e de políticas tradicionais baseadas no controle regional. Tal reprodução pode ser confirmada na análise dos dados eleitorais para governador do Estado desde a criação desta unidade da federação, em 1988.

Palavras-chave: identidade, política, eleição, estado do Tocantins.
\end{abstract}

\begin{abstract}
This article discusses the process of regional division and the actions of social subjects, producing regionalist discourse and symbolic representations which legitimize such actions. The subject was aroused in the debate about the division of the State of Pará in 2011. Taking the case of the State of Tocantins as a starting point, I shall use election data from state-governor races since the state came into being in 1988 to show that the way the debate on regional divisions has been conducted evinces the reproduction of social practices and traditional politics based on regional control.
\end{abstract}

Keywords: identity, politics, election, State of Tocantins.

\section{Resumen}

En el artículo se pretende discutir el proceso de división regional y la acción de sujetos sociales que producen discursos regionalistas y representaciones simbólicas que legitimen esa reivindicación. El debate en torno a la división del Estado de Pará, en 2011, suscitó este tema. Tomando el caso del Estado de Tocantins como punto de partida, queremos demostrar que la forma de desarrollarse el debate sobre las divisiones regionales revela prácticas sociales y políticas tradicionales basadas en el control regional confirmado a partir de los datos electorales para gobernador del Estado desde la creación de esta unidad de la federación, en 1988.

Palabras clave: identidad, política, elección, Estado de Tocantins.

\section{Introdução}

Recentemente, no fim de 2011, o Estado do Pará realizou um plebiscito no qual sua população foi consultada sobre a proposta de divisão regional de seu território em três unidades federativas: o estado do 
Pará, o estado do Tapajós e o estado do Carajás. Embora o resultado tenha sido contrário às fragmentações, o processo em si reacendeu o debate da divisão regional, que, segundo Martins (2001, p. 265-266), manifesta-se ao longo da história social e política brasileira, com o "fenômeno [...] de fragmentação das capitanias, depois das províncias e agora dos estados”.

O último processo de divisão regional vivido pelo Brasil ocorreu no fim da década de 1980, com a criação do estado do Tocantins em 1988 e sua implantação em 1989. A nova unidade federativa foi constituída a partir do desmembramento da porção norte do território do estado de Goiás, conhecida como "norte goiano". Segundo Cavalcante (2003), no fim do século XIX e ao longo do século XX ocorreram ao menos três movimentos que reivindicaram a autonomia político-administrativa da região: 18211823, 1956-1960 e 1985-1988.

No primeiro momento, 1821-1823, a oposição do norte ao centro-sul de Goiás estava na cobrança de impostos de captação de ouro. As minas do norte possuíam valores mais elevados a serem pagos aos cofres públicos do governo do que os das minas de Goyazes, no centro-sul. Segundo a historiadora Cavalcante (2003), percebe-se nas falas dos protagonistas de 1821 que a configuração daquele momento político apontava em duas direções para a sustentação do Governo Independente do Norte: a) ele poderia tanto estar articulado ao movimento de Independência do Brasil, ou b) aliar-se às Cortes de Lisboa. A posição de Joaquim Theotônio Segurado, ouvidor-geral da capitania de Goiás na época, foi a de manter-se fiel a Portugal, entretanto, com uma administração independente da que estava instalada no centro-sul de Goiás, do capitão-general Sampaio (Cavalcante, 2003).

No segundo momento, de 1956 a 1960, a autora faz uma alusão ao projeto de expansão do Estado brasileiro em direção ao interior, como uma das razões que fundamentaram a emancipação do norte de Goiás. Segundo Cavalcante (2003), isso foi possível porque o momento político nacional da segunda metade da década de 1950 havia sido marcado pelos projetos de expansão e integração do território brasileiro. Esses projetos configuraram-se promissores nas falas dos nortenses, que recriaram o discurso autonomista do "norte goiano", alimentados pelas diretrizes políticas do Governo Federal, que eram voltadas para a ocupação dos espaços vazios interioranos. Isso foi possível de ser constatado posteriormente, 
com a construção de Brasília pelo governo Juscelino Kubitschek, voltado para a interiorização das políticas de planejamento.

O terceiro momento, de 1985 a 1988, era pautado, sobretudo, pelas diferenças culturais e econômicas entre o norte e o sul de Goiás. Para Cavalcante (2003), enquanto o centro-sul goiano evidenciava uma sólida integração econômica com o mercado da região Sudeste do Brasil, acentuavam-se as diferenças internas entre o norte e o sul do estado, devidamente criadas com esse propósito. A expressividade dessa diferença foi tomada na construção do discurso autonomista regional, a partir das peculiaridades que identificariam, diferentemente, Tocantins e Goiás. Desta forma, observa-se que cada momento histórico, caracterizado por diferentes contextos, produziu suas argumentações que justificavam a formação do Tocantins.

A criação do estado do Tocantins não apenas redefiniu a fronteira goiana como também influenciou na reorganização regional do país, ao menos em parte. O "norte goiano", que integrava a região Centro-Oeste quando pertencia a Goiás, passou a fazer parte da região Norte, após alcançar sua autonomia e tornar-se o estado do Tocantins. Cumpre destacar que a Constituição de 1988, além criar o Tocantins, elevou à condição de estado os territórios federais de Roraima (ex-Rio Branco) e Amapá, criados em 1943, no governo de Getúlio Vargas: o primeiro, como área desmembrada do estado do Amazonas, e o segundo, do estado do Pará. Ou seja, ambos já integravam a região Norte do Brasil quando elevados a estados pela Constituição de 1988.

Como não pretendemos, neste artigo, estabelecer um debate que explore de maneira incisiva o conceito de região e seus desdobramentos, dedicaremos atenção ao processo de construção do discurso regionalista que produziu uma identidade para o Tocantins na década de 1980 e impactou de maneira substancial os resultados eleitorais para governador nos pleitos de 1988 a 2010. Consideramos que o discurso regionalista em tela esteve a serviço de uma elite política como instrumento de dominação e controle territorial. Isso vai ao encontro da reflexão de Gomes (2001, p. 72), quando o autor argumenta que "a aspiração da autonomia, baseada em um discurso regionalista, está a serviço de um grupo não exclusivo [...] que pretende impor uma identidade que o colocará na posição de controle ‘legítimo’ daquele território”. 
Para atender os objetivos expostos acima, este artigo discorre sobre a recente história política do estado do Tocantins, com recorte temporal a partir de sua criação, em 1988, pela Assembleia Nacional Constituinte (ANC). Como subsídio para este debate, apresentam-se os resultados das eleições para o poder executivo estadual (governador) no período de 1988 a 2010, coletados no Tribunal Superior Eleitoral (TSE). Os dados revelam a perpetuação do poder político concentrado em sujeitos envolvidos com o processo de criação dessa unidade da federação na década de 1980, os quais foram produtores dos discursos regionalistas formadores da identidade regional tocantinense.

\section{0 estado do Tocantins na Assembleia Nacional Constituinte de 1987/1988}

A Assembleia Nacional Constituinte (ANC) foi instalada em $1^{\circ}$ de fevereiro de 1987 e teve suas atividades estendidas até 1988, com a finalização dos trabalhos de elaboração da nova Constituição do país. Ela foi o espaço político oportuno para discutir e legislar sobre diversos assuntos de interesse nacional, entre eles, os projetos de criação de novas unidades federativas para o país, oportunidade para que diversas propostas de emancipações político-administrativas regionalistas pudessem se concretizar.

Entre as propostas de criação de novos estados, foi apresentado na $13^{\mathrm{a}}$ Reunião Ordinária da Subcomissão dos Estados, realizada em 12 de maio de 1987, o relatório com o anteprojeto da matéria que tratava da formação de seis novos estados na federação brasileira: a) estado do Juruá-AM; b) estado do Tapajós-PA; c) estado do Tocantins-GO; d) estado do Maranhão do Sul-MA; e) estado de Santa Cruz-BA; f) estado do Triângulo-MG.

O parecer rejeitou as seguintes propostas: a) estado de São Francisco, por haver propostas divergentes sobre a constituição dessa unidade da federação; b) estado do Meio Oeste, por envolver o Distrito Federal, além dos estados de Minas Gerais e Goiás; c) estado do Araguatins, por envolver áreas de dois estados, Goiás e Pará, e por não terem sido realizados debates a fim de verificar sua viabilidade.

Em 23 de maio de 1987, após discussões e debates na Subcomissão dos Estados sobre a primeira versão do relatório apresentado, o relator Siqueira Campos apresentou o anteprojeto para votação, que, resumidamente, no Capítulo II das Disposições Transitórias e Finais, propunha a 
transformação dos territórios federais de Roraima e do Amapá em estados e ainda criava os estados do Tocantins-GO, Maranhão do Sul-MA, Juruá-AM, Santa Cruz-BA, Tapajós-PA e Triângulo-MG, e devolvia a área do arquipélago de Fernando de Noronha ao estado de Pernambuco, entre outras questões. O anteprojeto foi aprovado, ressalvados os destaques apresentados. Após a votação de cada destaque, que envolvia diversos assuntos concernentes ao anteprojeto, o relatório foi encaminhado ao presidente da Comissão da Organização dos Estados, o constituinte José Thomas Nonô.

Em seguida, ocorreram discussões na Comissão de Sistematização, e o projeto de criação do estado do Tocantins foi aprovado para ser instalado em 45 dias após a realização de um plebiscito com a população local, mas ainda dependendo da aprovação do plenário da Assembleia Nacional Constituinte. Em $1^{\circ}$ de junho, o projeto foi apresentado ao plenário e aprovado por 320 votos favoráveis, 222 contrários e 10 abstenções.

As demais propostas não tiveram êxito, em função de "conflitos intra e inter regionais que obstaculizaram o processo [frustrando] as expectativas daqueles que lutavam pela transformação de suas regiões em um novo estado" (Martins, 2001, p. 272). Após ser aprovado em segundo turno pela ANC, sem a necessidade de realização de um plebiscito, o projeto de criação do estado do Tocantins foi promulgado pela nova Constituição da República Federativa do Brasil, em 5 de outubro de 1988.

Com a aprovação do estado do Tocantins pela Constituinte, a elite política regional passou a se preocupar com o tema da eleição para o primeiro governador. $\mathrm{O}$ assunto agitou o cenário político regional e provocou rupturas no movimento de emancipação do "norte goiano", que desde o início da década de 1980 vinha dando sustentação ao projeto emancipacionista. Essas divergências revelaram suas fragilidades ideológicas e os interesses privados envolvidos na questão.

Isso corrobora nosso argumento de que o estado do Tocantins foi criado com a intenção de atender aos anseios de grupos políticos tradicionais da região, interessados em consolidar seu domínio e poder sobre o território, sobretudo, com o apoio de setores da sociedade civil, como a União Democrática Ruralista (UDR) (Rodrigues, 2010). Evidência disso está na fala de Siqueira Campos, reconhecido popularmente como "pai” e "criador" do Tocantins, feita em 1988, quando se apresentava como candidato a governador "convocado pelas forças populares tocantinenses [...] 
encabeçando uma chapa de união ou não, para implantar a nova administração e construir um estado do qual possamos, os tocantinenses, orgulhar-nos [...]" (Campos, 1988, p. 12-144).

Os dados que apresentaremos a seguir mostram o quadro eleitoral do Tocantins desde a primeira eleição para governador, em 1988, até o pleito realizado em 2010. Neles ficam evidentes que as palavras de Siqueira Campos em 1988 representavam, entre outras coisas, um projeto político para a nova unidade da federação, que implicava no domínio e no controle do novo estado (que já se estende pelos seus 24 anos de existência) por uma elite que encontra respaldo para suas ações na memória do discurso autonomista da década de 1980, comportando-se como criadores legítimos da unidade federativa. Isto se revela no slogan "quem criou, merece” da campanha de Siqueira Campos para governador em 1988.

\section{As eleições no estado do Tocantins: 1988-2010}

O estado do Tocantins possui atualmente 139 municípios. Sua população, segundo dados do censo de 2010 do IBGE, é de um pouco mais de 1,380 milhão de pessoas. Na última eleição para governador, em 2010, compareceram às urnas 772.644 eleitores, mas os votos válidos totalizaram 692.021, segundo o Tribunal Superior Eleitoral (TSE, 2012a). Por meio das análises dos resultados dessa última eleição e daquelas realizadas a partir de 1988 para o poder executivo estadual, foi possível explorar o contexto político estadual.

Conforme os dados apresentados a seguir, constata-se que os resultados das urnas para o poder executivo estadual confirmam a perpetuação no poder dos produtores do discurso autonomista regional. Essas falas foram produzidas por aqueles que hoje ocupam cargos de poder político no estado. Se considerarmos que "uma dada região, como a própria ideia de região, é uma 'invenção histórica”' (Haesbaert, 2010, p. 68), os protagonistas do movimento criacionista do estado verificam, nas urnas, o reconhecimento do eleitorado a seus feitos históricos, qual seja, a criação do Tocantins.

Isso porque consideramos que a dominação desses sujeitos sociais sobre o poder executivo do Estado foi construída a partir dos sentidos histórico-geográficos que envolvem a criação do Tocantins. O movimento separatista da década de 1980 buscou elementos legitimadores desse dis- 
curso na diferenciação regional, baseados na produção da identidade regional tocantinense. Para Ribeiro (2001, p. 20), “o Tocantins, aos poucos, vai construindo suas instituições, seus símbolos, seus lugares de falar e seus porta-vozes que criaram uma representação para o Estado e seu povo, principalmente após a criação pela Constituição".

A expressividade dessa diferença foi tomada na construção do discurso autonomista regional, a partir das peculiaridades históricas, geográficas e culturais, para criar uma identidade regional que legitimasse a formação desse novo estado da federação. Segundo Haesbaert (2002, p. 408), "a busca de legitimidade para o projeto de uma nova unidade político-administrativa através da elaboração de uma identidade cultural como território [pode] ser decisiva na obtenção do apoio da população ao movimento".

Os dados eleitorais deste artigo revelam que os sujeitos políticos que ocupam o poder executivo estadual desde 1988 são os mesmos que produziram os discursos autonomistas e de diferenciação entre os estados do Tocantins e de Goiás no fim da década de 1980. Apresentamos abaixo a Tabela 1, com os candidatos eleitos em cada pleito para o executivo estadual desde 1988 até 2010.

TABELA 1- Governadores eleitos no estado do Tocantins entre 1988 e 2010

\begin{tabular}{|c|l|l|}
\hline Ano de eleição & Candidatos & Partido \\
\hline 2010 & José Wilson Siqueira Campos & PSDB \\
\hline 2006 & Marcelo de Carvalho Miranda & PMDB \\
\hline 2002 & Marcelo de Carvalho Miranda & PFL \\
\hline 1998 & José Wilson Siqueira Campos & PFL \\
\hline 1994 & José Wilson Siqueira Campos & PPR \\
\hline 1990 & Moisés Nogueira Avelino & PMDB \\
\hline 1988 & José Wilson Siqueira Campos & PDS \\
\hline
\end{tabular}

Fonte: Tabela elaborada pelo autor, com dados do Tribunal Superior Eleitoral.

Após a criação do Tocantins, os sujeitos sociais envolvidos em sua emancipação movimentaram-se no cenário político do novo estado da federação. Desde a primeira eleição, é nítido o "revezamento" de sujeitos políticos na administração do executivo estadual. De sete pleitos realizados para governador desde a criação do Tocantins, identifica-se a eleição direta de apenas três pessoas: José Wilson Siqueira Campos (quatro vezes), 
Moisés Nogueira Avelino (uma vez) e Marcelo de Carvalho Miranda (duas vezes).

A exceção é Carlos Henrique Amorim (Gaguim), do PMDB, que chegou ao poder executivo por eleição indireta realizada pela Assembleia Legislativa em 2009 (Gazeta do Povo, 2009), após a cassação do mandato de Marcelo de Carvalho Miranda pelo TSE, em 25 de junho de 2009 (Gallucci, 2009). Interessante destacar que Carlos Henrique Amorim era presidente da Assembleia Legislativa no governo de Marcelo de Carvalho Miranda, além de os dois pertencerem ao mesmo partido político, o PMDB.

Neste sentido, a eleição indireta de Carlos Henrique Amorim não representa uma ruptura com o governo anterior, dadas as estreitas relações políticas que esses sujeitos sociais possuíam entre si. Isto se torna ainda mais nítido na eleição de 2010, na qual Marcelo de Carvalho Miranda, então candidato a senador pelo estado do Tocantins, apoiou a candidatura de Carlos Henrique Amorim à reeleição para governador, mas este foi derrotado por José Wilson Siqueira Campos (PSDB) por uma diferença de 7.163 votos, em um universo de pouco mais de 692 mil votos válidos (TSE, 2012a).

Esse tipo de relação não foi algo novo no cenário político local. $\mathrm{Na}$ eleição de 2002, o candidato Marcelo de Carvalho Miranda teve sua candidatura apoiada por José Wilson Siqueira Campos. Já no pleito de 2006, os dois se enfrentaram e Marcelo de Carvalho Miranda venceu as eleições com uma diferença de mais de 30 mil votos, em um universo de mais de 660 mil votos válidos (TSE, 2012b) e se elegeu governador do Estado. Todo esse movimento supõe que uma mesma elite governa o Tocantins desde 1988, alternando no poder alguns de seus representantes, com distintas filiações partidárias, a cada pleito eleitoral.

Os dados eleitorais demonstram o controle político e a manutenção do poder exercido na região por uma elite política que remonta aos tempos de Goiás, composta por sujeitos que participaram do processo de criação do estado do Tocantins na década de 1980 e, mais especificamente, atuaram de maneira incisiva entre 1987 e 1988 na Assembleia Nacional Constituinte. Esta constatação ratifica a afirmação de Lencioni (2003, p. 194), quando a autora afirma que "o discurso em nome da identidade e dos interesses regionais pode servir para legitimar o poder numa determinada região”. 
Neste sentido, as representações simbólicas em torno da diferença entre goianos e tocantinenses, muitas vezes construídos sobre bases históricas (que davam legitimidade inquestionável à causa separatista, como o resgate dos movimentos de 1821-1823 e de 1956-1960 e de seus protagonistas) e geográficas (que justificavam as apologias espaciais do afastamento, do isolamento e do abandono regional) serviram como forma de perpetuar o domínio político de lideranças regionais sobre o Tocantins.

\section{Considerações finais}

O artigo apresentado revela que ainda há um amplo espaço de debates na geografia sobre a relação entre a produção da identidade regional, o exercício politico de elites regionais e os resultados eleitorais dessa associação. O caso tocantinense é um exemplo, em dois sentidos: a) é referência para novos processos de divisões regionais no país, como no Estado do Pará em 2011; b) demonstra o controle regional e o exercício do poder concentrado entre os sujeitos envolvidos com a causa separatista.

Nesse sentido, é de reconhecimento que os discursos de identidade e emancipação regionais são construídos dentro de contextos e enredos próprios e servem para atribuir novas significações a velhos espaços. Essas falas revestem-se de sentidos históricos e/ou geográficos para legitimar as fragmentações regionais. Não são raros os casos em que os argumentos, nos discursos separatistas, referem-se à dimensão espacial (afastado/isolado/abandonado) da região como meio de legitimar o processo.

Consideramos relevante também a constatação de uma identidade regional construída sob os argumentos da diferença, mas implantada sob o rigor de uma metamorfose. Os habitantes do "norte goiano" dormiram goianos em 31 de dezembro de 1988 e acordaram tocantinenses em $1^{\circ}$ de janeiro de 1989. O que ocorreu no Tocantins não se caracteriza como um encontro de duas identidades regionais diferentes, como o que ocorreu entre gaúchos e mineiros no cerrado, analisado por Santos (2008). No "norte goiano" assistimos a uma "metamorfose da identidade regional", em que a representação dos elementos da cultura goiana foi ressignificada para dar sentido ao novo, ao Tocantins, inventando e redefinindo a identidade regional.

No campo político, é nítido o envolvimento daqueles que atuaram, sobretudo, na Assembleia Nacional Constituinte de 1987-1988, no pro- 
cesso de criação do estado do Tocantins. E os resultados eleitorais confirmam a dominação política e o controle regional que esses sujeitos (e seus apoiadores/aliados/apadrinhados) exercem sobre a mais nova unidade federativa do país.

Os argumentos da apologia da criação do estado do Tocantins (como o slogan "quem criou, merece", de Siqueira Campos em 1988), das lideranças políticas regionais produzem um universo simbólico de ressignificação do "norte goiano" abandonado/isolado/afastado que atua como elementos que legitimam a divisão e autonomia da região para os populares/eleitores. Como resultado, essas lideranças encontram uma situação política confortável, capaz de perpetuar o controle político regional reatualizando, constantemente, os traços da identidade regional tocantinense.

\section{Referências}

CAMPOS, S. Discurso na Assembléia Nacional Constituinte. Diário da Assembléia Nacional Constituinte, Brasília, 28 jul. 1988, p. 12.144. (Comunicação Oral).

CAVAlCANTE, M. do E. S. R. O discurso autonomista do Tocantins. São Paulo: Edusp, 2003.

GOMES, P. C. da C. O conceito de região e sua discussão. In: CASTRO, I. E. de; GOMES, P. C. da C.; CORREAA, R. L. (Org.). Geografia: conceitos e temas. 3. ed. Rio de Janeiro: Bertrand Brasil, 2001. p. 49-76.

GAZETA DO POVO. Em eleição indireta, Tocantins escolhe novo governador. Gazeta do Povo, Curitiba, 9 out. 2009 (Vida Pública). Disponível em: <http://www. gazetadopovo.com.br/vidapublica/conteudo.phtml?tl=1\&id=932242\&tit=Emeleicao-indireta-Tocantins-escolhe-novo-governador>. Acesso em: 10 mar. 2012.

GALLUCCI, M. TSE decide cassar mandato do governador de Tocantins. O Estado de S. Paulo, São Paulo, 26 jun. 2009 (Política). Disponível em: <http://www. estadao.com.br/noticias/nacional,tse-decide-cassar-mandato-do-governador-de tocantins,393248,0.htm>. Acesso em: 10 mar. 2012.

HAESBAERT, R. Regional-Global. Dilemas da região e da regionalização na Geografia Contemporânea. Rio de Janeiro: Bertrand Brasil, 2010.

HAESBAERT, R. Gaúchos e baianos no "novo" Nordeste: entre a globalização econômica e a reinvenção das identidades territoriais. In: CASTRO, I. E. et al. (Org.). Brasil: questões atuais da reorganização do território. 2. ed. Rio de Janeiro: Bertrand Brasil, 2002. p. 367-415.

LENCIONI, S. Região e geografia. São Paulo: Edusp, 2003.

MARTINS, H. T. A fragmentação do território brasileiro: a criação de novos estados no Brasil. Caderno CRH, n. 35, p. 263-288, jul./dez. 2001. 
RIBEIRO, F. de A. A invenção do Tocantins: memória, história e representação. Dissertação (Mestrado em História) - Faculdade de Ciências Humanas e Filosofia, Universidade Federal de Goiás, Goiânia, 2001.

RODRIGUES, J. C. Estado do Tocantins: política e religião na construção do espaço de representação tocantinense. São Paulo: Blucher, 2010.

SANTOS, R. J. (Re)Ocupação do cerrado: novas gentes, outras identidades. In: ALMEIDA, M. G. et al. (Org.). Geografia e Cultura: os lugares da vida e a vida dos lugares. Goiânia: Vieira, 2008. p. 98-136.

TSE - Tribunal Superior Eleitoral. Estatísticas de Resultados - Resultado da Eleição. Eleição 2010. Disponível em: <http://www.tse.jus.br/eleicoes/eleicoesanteriores/eleicoes-2010/eleicoes-2010/estatisticas> . Acesso em: 15 mar. 2012a.

TSE - Tribunal Superior Eleitoral. Consulta de Resultados Eleitorais. Eleição 2006. Disponível em: <http://www.tse.jus.br/eleicoes/eleicoes-anteriores/eleicoes-2006/ informacoes-quadro-partido-cargo >. Acesso em: 18 mar. $2012 \mathrm{~b}$.

Jean Carlos Rodrigues - Doutor em Geografia pela Universidade Estadual Paulista - Professor da Universidade Federal do Tocantins. 